\title{
An International Discourse on Culture in the Classroom: Teachers from Four Countries Share their Perspectives
}

\author{
Michael Lovorn ${ }^{1, *} \&$ Robert Summers ${ }^{2}$ \\ ${ }^{1}$ Social Studies Education, The University of Pittsburgh, Pittsburgh, USA \\ ${ }^{2}$ The State University of New York, Buffalo State, SUNY, USA \\ *Corresponding author: Social Studies Education, The University of Pittsburgh, \\ Pittsburgh, USA E-mail: mlovorn@bamaed.ua.edu
}

Received: January 21, 2013 Accepted: February 19, 2013 Published: April 30, 2013

doi:10.5296/ije.v5i2.3097 URL: http://dx.doi.org/10.5296/ije.v5i2.3097

\begin{abstract}
Researchers explored perspectives of teachers from four countries about how they recognize and address their students' cultural backgrounds; how they incorporate students' culture into their teaching; and what impact their efforts have on the learning environment. Participants ( $n$ $=41$ ) were engaged in an online discussion board and posted thoughts and responses to other participants. Researchers performed a content analysis to identify patterns in participants' observations and perspectives, which revealed that most participating teachers recognize and address students' cultural backgrounds in academic, affective, and social contexts. Teachers who attend to these needs enjoy effective academic connections with students, have a heightened sense of confidence in their ability to connect with students, are able to devote ample time to the content they are teaching, and deal with fewer behavioral issues.
\end{abstract}

Keywords: culture; international; classroom; discourse; teachers 
The global community becomes more interdependent every day. The Information Age has ushered in an immeasurable degree of hyper-connectivity that transcends economics, culture, and education, and demands that we increase our awareness of one another. Teachers must keep pace by developing critical understandings of the cultural backgrounds of students in their ever diversifying classrooms, and work together to facilitate learning environments that are stimulating and sensitive to all stakeholders. Studies show critical understandings of students' academic, affective, and social needs can lead to better teaching, more impactful school leadership, and more effective classroom management (Bennett, 1993; hooks, 2003; Zeichner \& Hoeff, 1996). The purpose of this study was to explore perspectives and discussion threads among K-12 teachers at schools in four countries (Brazil, Ireland, Mexico, and the United States) about: 1.) how they recognize and address their students' cultural backgrounds; 2.) how they incorporate students' culture into their teaching; and 3.) what impact their efforts have on the learning environment.

For purposes of this study, culture is defined as a person's conceptions of identity, gender, race, class, and other components of her/his background. Scholars generally agree that culture is indicated by how humans perceive themselves, their communities, and society as a whole. These self-perceptions are significant because research has revealed that such internal and reflective perceptions of culture commonly influence our ideas of citizenship (Sunal, Christensen, Shwery, Lovorn \& Sunal, 2010), sense of belonging (Museus \& Maramba, 2011), societal roles (Powell, 2009), communication (Horner, 2012; Speece, 2012), and education (Lee \& Recchia, 2008; Quinn, 2011). Studies also suggest that K-12 teachers' understandings of their students' cultural backgrounds and means of cultural expression impact teaching, learning, and the classroom environment (Lovorn, Szymanski Sunal, Christensen, Shwery, \& Sunal, 2012), and that most teachers claim to recognize the impacts of culture on learning dynamics, student morale, and performance (Lovorn \& Summers, 2011).

With this knowledge, researchers sought to engage professional teachers in discourse on how they utilize their understandings to meet the needs of diverse student populations. The perspectives of teachers in this population were of particular interest and were targeted in this study because, in addition to being active inservice teachers, they were students of graduate courses taught by the researchers. Researchers agreed that although participants' perspectives are not likely generalizable, this study could reveal patterns of thought, experiential tendencies, and other information that could inform the graduate program. Researchers realized this unique connection to participants could present biases that might impact data collection and analysis. Researchers attempted to address these biases by reminding participants the qualitative research data would be used to inform the program, and thus, their open and honest perspectives were critical to the study. Participants were also encouraged to select pseudonyms to obscure their identities.

\section{Research Questions}

To initiate this discourse among teachers in different countries, researchers asked the 
following questions:

1.) What are teachers' perceptions about how students' cultural backgrounds are recognized in the school?

2.) How do teachers incorporate students' culture into their teaching?

3.) What impacts do teachers' efforts have on the learning environment?

\section{Method and Data Collection}

Researchers used a free-access, wiki-type online discussion board to facilitate discourse between June 2011 and March 2012. Participants were professional K-12 teachers in Campinas, Brazil $(n=17)$; Limerick, Ireland $(n=6)$; Mexico City, Mexico $(n=8)$, and the Tuscaloosa, Alabama, USA $(n=10)$. Of all participants $(n=41), 32$ were female and 9 male; 29 identified themselves as Caucasian/European, 9 identified themselves Hispanic/Latino(a), and 3 identified themselves as Black/African American. About $68 \%$ of the participants $(n=$ 28 ) reported that they have been teaching professionally for $0-5$ years, about $20 \%(n=8)$ reported that they have been teaching professionally for 6-10 years, and about $12 \%(n=5)$ reported that they have been teaching professionally for more than 10 years. Fourteen participants identified themselves as middle or high school teachers (grades 6-12), and 27 identified themselves as elementary level teachers (grades K-5). It should be mentioned that the schools in Brazil and Mexico are American-style private schools. Instruction is delivered in English, and students are prepared to attend universities in the United States.

Participants were able to see and respond to posts from each of the aforementioned locations. In an effort to generate rich dialogue and bring uniformity to the collection of data, each participant was asked to make at least three posts to her/his choice of threaded discussions related to the research questions; one original post, and two response posts to thoughts of others. Once posts began, the researchers did not interfere with data collection by directing or redirecting discourse. Researchers did send occasional e-mails to all participants to remind them to post their comments. Most participants' highly contextualized responses came in narrative form.

Content analysis is particularly appropriate for narrative, contextual data that have been collected in an electronic format (Neuendorf, 2002). Researchers determined the electronic format would be the most revealing and least intrusive means by which participants could share their perspectives. Content analysis was also deemed appropriate for this study because researchers have significant experience with this method, having performed no less than four content analyses in similar settings. Researchers also included a narrative inquiry model (Clandinin \& Connelly, 2000) to interpret participants' posts and responses, and implemented strategies to protect the authenticity and trustworthiness of the data (Lincoln \& Guba, 1985). These protective strategies included participant debriefing, triangulation of data analysis, and prolonged engagement among researchers and participants. Posts and responses were then coded by two primary researchers and two additional research assistants, and categorized 
with special focus on research questions as interconnected themes. Prior to coding activities, the two primary researchers and two research assistants were normed on the content analysis structure and the narrative inquiry model.

Participants in each of the four countries were presented with the research questions as prompts for discussion, and given a few days to reflect on their feelings and experiences before responding. Participants then joined the online discussion and were encouraged to make posts that they were particularly passionate about and at times that were convenient to them. Again, researchers sent several reminder e-mails to encourage participants to read and respond to the posts of other participants. Researchers monitored posts for a period of about 9 months. Each of the participants had posted at least one original comment or response by September 2011, and each participant had made at least three posts by March 2012.

\section{International Discourse on Culture}

Three themes emerged from the threaded online discussions: 1.) most teachers recognize and actively address their students' cultural backgrounds in the classroom; 2.) teachers use a wide variety of creative and involved strategies to incorporate students' culture into their teaching; and 3.) most teachers believe their efforts to recognize and incorporate students' cultures into their classrooms are critical to students' success and development. Excerpts of threaded conversations have been included to demonstrate themes.

\section{Theme 1: Teachers Recognize and Address Students' Cultural Backgrounds}

Participants discussed their perceptions of individual and institutional recognition of cultural diversity in their classrooms and schools. This discussion began with descriptions of recognized population growth patterns in each location, and evolved into an exchange of observations and approaches to accommodating ever-diversifying student populations. Third year English/Language Arts teacher Liam from Limerick, Ireland initiated this discussion by stating that his school is increasing in diversity:

"[My high school] is becoming more diverse each year, it seems. Just this year we have had several students come from India and Turkey. We also have several Korean students. Our school does not have a policy for addressing the needs of students from other cultures; however, when I have a new student from another culture, I always like to make them feel as though they are part of my classroom community. I want to make them feel as though they belong here. I may address it differently with different students. I invite some to talk about their culture. I also give them opportunities to share arts or poetry from their native country. My local students who have been in Limerick all their lives always like learning about different cultures as well, so they are quite respectful. It's usually a good experience for everyone."

Margaret, a first year teacher in Mexico City, responded to Liam's post with a description of the cultural recognition in her school and a couple of questions:

"This is my first year at [the Mexico City school], but I can say that we have a diverse 
student body too. Most of our students are from wealthy families in Mexico City. They come here to be prepared for college in the U.S. But we also have students who are here because their moms and dads work in international business. Especially from Asia. They come from the South Korea, Japan, Thailand, and Taiwan. Many of their parents are very active in the school, so it is easy for us to recognize their cultures. We have a culture fair in the spring, and the parents help set this up. They bring in cultural foods and help teach the students about Asian culture. I have a question for [Liam]. Do you require your students to talk about their culture, or it is a voluntary thing? What if students are shy or apprehensive about their English?"

Liam responded:

"No, I do not require them to stand up in front of the class and talk about their culture. I really just give them the opportunity and tell them we'd all like to hear about their culture if they feel comfortable sharing with classmates. This is probably the best approach. I seek to recognize their culture, not make them feel uncomfortable or nervous about it all. I only suggest they share poetry or art from another culture because this is an English class. I want them to be able to share a bit of their background. I do not grade them on these activities. Also, most of the students who have come to my class from other countries are proficient in English and do not need such language accommodation, but if they did, I could allow them to express themselves in different ways. I have found art is a very good way to do this."

To this, Lisa, in her eleventh year as a high school social studies teacher, added:

"This is similar to what I do with new students. They don't have to be from a different country to have a different culture. I like to give any new students an opportunity to share a little about where they came from and who they are. To me, this is one of the best ways to make everyone feel safe and secure in my room. And I don't just do this for new students. At the first of each semester, I have an activity called 'What Makes Me Different.' I go around the room and have each student share something that makes them different. I begin by telling the class what makes me different. I usually tell them that I collect old records, which makes me different. Then I usually tell them I am multi-racial because my father is African American and my mother is white. Our school is about 60\% African American and 40\% white, so they are all interested to know this. The idea is to make each student feel good about being a unique individual, and to know that I celebrate diversity in my classroom."

Rebecca, who is in her second year as an elementary school teacher in Limerick, asserted: "It is so important to make all students feel welcome in the classroom. For many years, and perhaps still to a degree, Irish school has been about learning and promoting Irish culture." Later, she added: "As an Irish woman, I understand this, but we also need to be aware of the increasing cultural diversity in our schools." Second year elementary teacher in Brazil, Jonna, spoke of effort in her school to accomplish this recognition:

"Our school has a great approach to promoting a multicultural learning environment. 
We are always looking for ways to recognize all the cultures that make up our student body. We have craft fairs, and international food days, and our principal is really good about doing little things like putting various flags up around the school. We are definitely a culture-friendly school. Interestingly, there are really two dominating cultures here: Brasilian and American. Most of our students are Brasilian, so obviously we recognize their culture and heritage. But we are also an American-style prep school and all instruction is delivered in English, so that is a big influence too. Both of these dominant cultures are accepting of others, so that is good for everyone."

Josh, a first year high school science teacher in Alabama, shared his observations of his school's very different approach:

"Everyone may claim they are welcoming of diversity in their schools, but I am not experiencing that at my school. Our school system claims to welcome students from different cultures, but the dominant culture is conservative Christian, and everywhere you look, you see unspoken messages that reinforce this as the only really respected culture. It's like we're saying you can come here but you have to acclimate. It's even true in how we teach."

To this, Anna, a first year science teacher in Ireland, queried: "Isn't this really a bit true of all cultures though? Aren't we all somehow promoting our own culture as dominant?" First year high school social studies teacher replied: "Yes, this might be true. That's certainly the case in not just Alabama, but the U.S. as a whole." Greg went on to add:

"I do understand what Josh is saying. There is an expectation in this part of the U.S. that teachers will conform to this conservative culture. Teachers are definitely expected to be conservative role models, so that means there is an expectation that they will pass this on to their students. So yes, we can recognize different cultures, as long as we all agree that American culture, more specifically Southern conservative culture, is still the best."

Donna, an 11-year veteran elementary school teacher in Brazil, responded: "How interesting! [Our school] celebrates our students' different backgrounds. Most of our students' families are Christian too, and we are an American school, but cultural diversity is really something we all try to highlight." Third year elementary teacher Marcia at the same school in Brazil added: “... we want all students to know their culture is who they are, and we don't want to change this", and added: "It is very important to teach children to be proud of their cultural identity and each child is special."

From Mexico City, Rebecca, an upper elementary school teacher with four years of experience, echoed Margaret's sentiments and discussed her perceptions of her school's approach to recognizing culture:

"I am happy we celebrate the cultures of our students. The culture fair is a wonderful opportunity for us to demonstrate that we are interested in everyone's culture and can learn from it. And I do learn something new at the culture fair each year. Last year, one of our Korean students' (with help from her mother) set up a booth to write students' names in Korean characters. It was very popular, and we all learned a little about the 
Korean alphabet."

The discourse revealed that each school represented in the study claimed to have some approach or institutional program designed to recognize students' cultural backgrounds, although not all teachers felt their schools effectively did so. Some respondents felt some of their school's efforts amount to little more than a patronizing nod to cultures other than the dominant one. For instance, three-year veteran special education teacher Gavin said of his Irish school's approach: "I know [school administrators'] intentions are good, but many of our attempts to recognize culture as really only scratch the surface of real, meaningful cultural diffusion." To this, Candice, in her second year as a middle school math and science teacher in Brazil, added: "Many do recognize culture in our school, but this is not true of everyone. It really differs from teacher to teacher."

Despite these sentiments, however, coded data revealed a vast majority of study participants favored classroom and school related activities that recognize and address students' culture and cultural expressions. No less than 36 of the 41 participants posted comments describing culture-related activities (most commonly, individual or small group culture presentations, and culture festivals) they employ in their classes. This was true even for participants in schools with no established culture program.

It appeared that participants' schools in Brazil and Mexico have established and maintain active programs that recognize and appreciate students' cultural backgrounds. Based on participants' responses these programs may not have such a high degree of institutional support in Ireland and Alabama, and therefore, the responsibility devolved upon each teacher to create an atmosphere that is warm and welcoming to students who have backgrounds other than that of the dominant culture. Kimberly, a first year high school social studies teacher in Alabama summed it up in this way: "Regardless of what the school says or does, I will make my classroom a place that is welcoming to all my students. I want them all to know that we are all members of the same community." Of particular interest to researchers was this evidence that regardless of the school environment, participants overwhelmingly recognized the need for student engagement in culture-related activities, and developed ways to facilitate such activities in their classes.

\section{Theme 2: Teachers Use Strategies to Incorporate Students' Culture into their Teaching}

Research suggests a positive correlation between teachers' perceptions of and attention to their students' backgrounds (cultural as well as socioeconomic) and students' academic and behavioral responsiveness, empowerment, motivation and performance (Chiu \& Chow, 2010; Edwards, 2010; Lovorn \& Summers, 2011), and as discourse continued, a second theme emerged from the data to support these findings. As participants began to discuss how they incorporate students' cultural backgrounds into their teaching, it became clear that most of the participants perceived themselves as facilitators of students' success through cultural expression. Data coding and analysis revealed that a majority of participants $(n=29)$ posted at least one comment in which they articulated their particular roles and facilitations in this regard. For instance, Charles, a second year high school social studies teacher in Alabama stated: 
"As a history teacher, I have a very important role in the lives of my students. If I don't connect the dots and make history relevant, students may think it's not important or that it doesn't matter to them. So, in my class, I give students opportunities to apply history to their lives. I begin many lessons by giving students a handout to take home and fill out with their parents or grandparents. Basically, the handout asks questions to see what they already know about a topic. It's kind of like the first part of a KWL. When students bring them back, we often discuss how different cultures perceive things differently. It's a good way to make my lessons more meaningful to them."

To this, Lisa from Alabama replied: "Charles, that is such a good idea! It's good that you are bringing parents into the classroom one way or another. Parents are an important part of culture in the classroom." Fifteen-year veteran primary grades teacher, Patty, also responded:

"Yes, if the teacher is going to allow students to discuss their culture, the parents must be involved. They teach the culture to the child. I invite my students' parents to come speak to the class. They can present anything to the students. Sometimes they show pictures when they were children. Sometimes they bring snacks for the children. We always learn something about their culture."

Daniel, a nine-year veteran high school social studies teacher in Mexico City, shared a similar approach:

"I like Charles' idea too. I do something similar with my students. When I am teaching history, I ask students to help me interpret or describe the event or person through different perspectives. We use a history textbook from the U.S., so this is interesting and fun for my students because they can compare how their culture reveres someone like Antonio López de Santa Anna, and then see how he is presented in the U.S. History."

Several participants responded to Daniel's post. Gavin in Limerick, Margaret and Rebecca in Mexico City, and Yvonne, a fifth grade teacher in Campinas, each shared similar projects they designed to incorporate students' cultural backgrounds into lessons. These examples centered on the use of perspective and multiple realities to engage students in critical thinking about subject matter. Studies reveal that teachers who teach with attention to different perspectives and multiple realities, particularly in the context of social studies, advance their students' development as free and independent thinkers (Admiraal \& Wubbels, 2005; Banks, 2007; Gehlbach, 2011).

As in Charles' teaching example above, many of the perspectives and multiple realities discussed by participants were culture-specific, and prompted students to research their feelings and backgrounds to make informed contributions in class discussions, and to give more consideration to the cultural perspectives of their classmates. Interestingly, posts revealed that there was some difference in the ways different teachers introduced culture-related activities in class. Most participants, like Charles, reported that they initiate culture-related activities for their students by assigning some sort of background investigations, while others spoke of how they favor allowing such activities to develop in a more organic way, examining cultural nuances and differences as they come up in class. Josh, 
a first year high school science teacher in Alabama, posted: "My lessons don't usually allow for students' different interpretations of scientific concepts, but when students ask about how certain things impact them, I make sure we take class time to address it."

Overall, a majority of participants $(n=29)$ demonstrated that they not only recognize and address different cultures in their classes, but orchestrate either teacher-initiated activities, or student-initiated class discussions. Naturally, with this personal investment and immediate sense of relativity, students (as well as their teachers) may become more aware of the cultures represented in the classroom, and more attuned to their own cultural biases (Banks, 2007; Bennett, 1993; Freire, 2000; hooks, 2003). These findings led to the third theme that emerged from the discourse: a discussion on the necessity and critical nature of this multi-level, student-centered approach.

\section{Theme 3: Teachers believe their Efforts are Critical to Students' Success and Development}

"I believe culture studies should be a part of our regular curriculum", said Jorge, a veteran high school social studies teacher in Mexico City. "It may be", he continued, "the most important thing we can teach students before they enter the real world." Ryan, a second-year high school social studies and economics teacher in Alabama, added to Jorge's assertion:

"Yes, this is a critical skill. Students need to know how to respect and get along with other members of their community. They need to know how to care, especially when we consider that many of the new jobs that are in services instead of production. People help others more when they try to understand them."

This exchange initiated the third and final theme of the online international discourse. Participants were not only passionate about recognizing culture in their classrooms and incorporating it into their teaching, but they were adamant about the need for more structured and institutional efforts to speak to culture in the school. Liam (Limerick), Maria (Mexico City), and Kimberly (Alabama) each posted comments supporting Ryan's statement. Liam agreed that caring is of the utmost importance. He went on to add: "As someone who grew up in a place where there was a lot of fighting, I know understanding is of the greatest importance. Teachers have immense responsibilities to provide understanding many children don't receive at home."

Along with this adamancy, first-year elementary teacher Jennifer (Mexico City) opined: "It is true we need to not only include culture, but teach it in our classes...", and then asked: "... but who will teach it? Who is qualified to teach a culture class?" This question aroused some discussion on teacher responsibilities and expectations. Most of the participants who posted responses agreed that this was a good question, but indicated that all teachers should take on these and related responsibilities.

For instance, Katherine, a Limerick elementary teacher in her fifth year, shared her opinion: "We are all qualified to teach children about culture, cultural exchange, and cultural diffusion. Our students need to be exposed to culture studies as much as they need reading and writing." Katherine then stated she has been trying to establish a cultural exchange between her classes 
and students in other countries, but that she has encountered multiple problems in this effort, including settling on a curriculum or series of projects, securing the headmaster's endorsement, and identifying a school/classroom that is willing and able to make regular exchanges. "It is a lot of work", she exclaimed.

First year English/Language Arts teacher Megan from Alabama added: "Our biggest problem in the U.S. is finding time to do something like this. We have so many tests and expectations." To this, five-year veteran middle school teacher Caroline in Brazil stated: "We do this at [our school], but there is no curriculum for it. We are still glad we do it because we know how important our role is, especially for students who will leave their culture to go to college in the U.S."

\section{Discussion}

Research on the impacts of teachers' attention to cultural background and cultural expression in the classroom indicates that learning environments rich in cultural diversity are more likely to produce students who are liberally progressive, tolerant, empathetic, and sensitive (Bennett, 1993; Freire, 2000; Joseph, 2008; Summers \& Lovorn, 2012). Empathetic and culturally sensitive students make good global citizens and stewards of the earth. Researchers have also demonstrated that teachers' perceptions of their students' cultural background and efforts to address them in the classroom have significant impacts on these dynamics (Lovorn, Sunal, Christensen, Shwery, \& Sunal, 2012; McLaren \& Kincheloe, 2007).

The content analysis model used in this study does not allow for generalizations across all learning environments; however, participants demonstrated that for the four sites included in this discussion, recognizing and addressing students' cultural backgrounds is of the greatest significance to students' academic and behavioral success. Participants $(n=29)$ discussed how their facilitation of students' cultural expressions leads to increased and more meaningful participation in class activities, particularly among ethnic or cultural minorities. Participants $(n=23)$ also pointed out that their efforts often lead to more predictable student behavior, and fewer behavioral disruptions.

These teachers report that their students are more comfortable in learning environments that incorporate strategies to recognize and accommodate various cultural backgrounds, and promote cultural awareness, cultural sensitivity, and critical pedagogy. Participants feel their focused attention to these characteristics and attributes provides them with dynamic opportunities to facilitate richer social and academic learning experiences for each student in their classes. Findings such as these challenge teachers in ever-diversifying schools to explore means by which they may positively impact the classroom dynamic. 


\section{References}

Admiraal, W., \& Wubbels, T. (2005). Multiple voices, multiple realities, what truth? Student teachers learning to reflect in different paradigms. Teachers and Teaching: Theory and Practice, 11(3), 315-329. http://dx.doi.org/10.1080/13450600500105668

Banks, J. A. (2007). Introduction to multicultural education $\left(4^{\text {th }}\right)$. Boston, MA: Allyn \& Bacon.

Bennett, M. (1993). Towards ethnorelativism: A developmental model of intercultural sensitivity. In R. M. Paige (Ed.), Education for the intercultural experience. (pp 1-71). Yarmouth, ME: Intercultural Press. http://dx.doi.org/10.1016/0147-1767(93)90017-3

Chiu, M. M., \& Chow, B. W. Y. (2010). Culture, motivation, and reading achievement: High school countries in 41 countries. Learning and Individual Difference, 20(6), 579-592. http://dx.doi.org/10.1016/j.lindif.2010.03.007

Clandinnin, D., \& Connelly, F. (2000). Narrative inquiry: Experience and story in qualitative research. San Francisco, CA: Jossey-Bass.

Edwards, C. (2010). Exploring students' and teachers' perceptions of the cultural responsiveness in three programs for African American students. (Doctoral dissertation). Retrieved from ERIC database. (ED516524)

Freire, P. (2000). Pedagogy of the heart. New York, NY: Continuum.

Gehlbach, H. (2011). Making social studies social: Engaging students through different forms of social perspective taking. Theory Into Practice, 50(4), 311-318. http://dx.doi.org/10.1080/00405841.2011.607394

hooks, b (2003). Teaching community: A pedagogy of hope. New York, NY: Routledge.

Horner, R. (2011). Culture, communication, and competence: A commentary on variables affecting social and academic behavior. Journal of Behavioral Education, 20(4), 306-311. http://dx.doi.org/10.1007/s10864-011-9139-4

Joseph, C. (2008). Difference, subjectivities and power: (De)colonizing practices in internationalizing the curriculum. Intercultural Education, 19(1), 29-39. http://dx.doi.org/10.1080/14675980701852350

Lincoln, Y., \& Guba, E. (1985). Naturalistic inquiry. New York, NY: Sage Publications.

Lee, Y. J., \& Recchia, S. L. (2008). "Who's the boss?" Young children's power and influence in an early childhood classroom. Early Childhood Research \& Practice, 10(1). http://dx.doi.org/10.1080/14623940802207394

Lovorn, M., \& Summers, R. (2011). Recognizing and speaking to culture in the international classroom. The Leader, 25(2), 22-26.

Lovorn, M., Szymanski Sunal, C., Christensen, L., Shwery, C. \& Sunal, D. (2012). Who's in control? Teachers from five countries share perspectives on power dynamics in the learning environment. Journal of Research in International Education, 11(1), 70-86. 
http://dx.doi.org/10.1177/1475240911435869

McLaren, P., \& Kincheloe, J. L. (2007). (eds) Critical pedagogy: Where are we now? New York, NY: Peter Lang.

Museus, S. D., \& Maramba, D. C. (2011). The impact of culture on Filipino American students' sense of belonging. Review of Higher Education, 34(2), 231-258. http://dx.doi.org/10.1002/aehe.3606

Neuendorf, K. A. (2002). The content analysis guidebook. Thousand Oaks, CA: Sage Publications.

Powell, K. C. (2009). The role of concept of self and societal expectations in academic and career achievement. Journal of Adult Education, 38(2), 32-40.

Quinn, J. (2011). Education and culture. Florence, KY: Routledge, Taylor \& Francis Group.

Speece, M. (2012). Learning style, culture and delivery mode in online distance education. US-China Education Review, A(1), 1-12.

Summers, R. \& Lovorn, M. (2012). International teachers' perceptions of classroom intersections of culture and language: Impacts on ESL education in South America. Journal of Education and Social Research, 2(3), 11-18. http://dx.doi.org/10.5901/jesr.2012v2n3p11

Sunal, C., Christensen, L. S., Shwery, C., Lovorn, M., \& Sunal, D. (2010). Teachers from five nations share perspectives on culture and citizenship. Action in Teacher Education, 32(2), 42-55. http://dx.doi.org/10.1080/01626620.2010.10463549\#

Zeichner, K., \& Hoeff, K. (1996). Teacher socialization for cultural diversity. In J. Sikula (Ed.), Handbook of research on teacher education (pp. 525-547). New York, NY: Macmillan.

\section{Copyright Disclaimer}

Copyright reserved by the author(s).

This article is an open-access article distributed under the terms and conditions of the Creative Commons Attribution license (http://creativecommons.org/licenses/by/3.0/). 